\title{
Pricing and Warranty Level Decisions for New and Remanufactured Short Life-Cycle Products
}

\author{
Shu-San Gan ${ }^{1 *}$ I Nyoman Pujawan ${ }^{2}$
}

\begin{abstract}
Remanufacturing has become more prominent as a recovery process to mitigate the massive disposal of short life-cycle product at its end-of-use. However, remanufactured product is often perceived to be inferior to new product, and it has lower value in consumer's willingness to pay. To increase the perceived quality of the remanufactured product, manufacturer offers a warranty, since one of the three roles possessed in warranty is being a signal to product reliability. This paper studies the pricing decisions and warranty level decision for new and remanufactured products in a closed-loop supply chain consists of a manufacturer and a retailer. The optimization modeling is performed under Stackelberg game with manufacturer as the leader. We found that higher expansion effectiveness coefficient would increase the supply chain profit. Also, there is an interval of demand's speed of change, where the total profit would be at its highest. The optimum warranty level can be achieved regardless the initial warranty level set at the beginning of retailer's optimization. Furthermore, the remanufactured product's wholesale and retail prices are influenced by the expansion effectiveness coefficient.
\end{abstract}

Keywords: Pricing, remanufacturing, warranty, short life-cycle product.

\section{Introduction}

In this modern society, we have witnessed that throw-away behavior has increased significantly. It can take the form of disposable products, style or fashion that is shortly replaced by newer designs, new or added features to a product that are so appealing and have convinced customer to buy new product while the older one is still perfectly functioning. The obsolescence notion has directed some products to have shorter life cycle. Demand of these products may increase rapidly in the introduction phase, but decrease fast when newer models or products emerge. Electronics products are among classes of products that extensively exposed to obsolescence, due to rapid technology advancement as well as customers desires to buy the latest model. These types of obsolescence were introduced by Packard [1] as obsolescence of function and obsolescence of desirability. In electronic industry, product life cycle is also getting shorter as a result of rapid technology advancement (Hsueh [2]). As for technology based commodities such as mobile phones and computers, Lebreton and Tuma [3] found that those commodities have shorter innovation cycle, which makes the previous generation or model becomes obsolete faster, either functionally and psycho logically.

\footnotetext{
1 Faculty of Industrial Technology, Mechanical Engineering Department, Petra Christian University, Jl. Siwalankerto 121-131 Surabaya 60238, Indonesia. Email: ganshusan@petra.ac.id

2 Faculty of Industrial Technology, Industrial Engineering Department, Institut Teknologi Sepuluh Nopember Surabaya, Kampus Keputih Sukolilo, Surabaya 60111, Indonesia. Email: pujawan@ie.its.ac.id

* Corresponding author
}

Shorter product's life-cycle has negative impact towards sustainability because there is an increase in disposed products when customers want newer products and discard the old ones. Also, the tendency of unnecessary increased obsolescence would drive more production of newer products than actually needed, which increase the consumptions of natural resources and energy.

Remanufacturing is one option to manage products at their end-of-use which offers opportunity for complying with regulation while maintaining profitability. It is a process of transforming used product into "like-new" condition, so there is a process of recapturing the value added to the material during manufacturing stage (Lund and Hauser [4], Gray and Charter [5]). There are pros and cons on short life-cycle product remanufacturing, because several studies claimed that durability is one of critical factors for successful remanufacturing. However Gan et al. [6] has shown that remanufacturing of short life-cycle product is rewarding economically as well as environmentally, and provide a framework for remanufacturing of such product.

The importance of pricing strategy for new and remanufactured products has been discussed widely in the recent years. The underlying issues in introducing remanufactured product side by side with the new product is cannibalization. However, Atasu et al. [7] conclude that remanufacturing does not always cannibalize the sales of new products, when a proper pricing strategy is applied. Furthermore, Souza [8] shows that introducing remanufactured product to the market alongside with the new product could bring a market expansion effect. 
Therefore, pricing decision is an important task in an effort to gain economic benefit from remanufacturing practices.

Pricing model for differentiated new and remanufactured product has been investigated in several studies. From manufacturer's point of view, Atasu et al. [9] propose pricing models under several scenarios that represent the effects of three drivers of remanufacturing profitability linked to market demand. The drivers are (1) direct competition with Original Equipment Manufacturer (OEM), (2) the existence of green segment, and (3) speed of market growth as a property product life cycle. In these models, new and remanufactured products are differentiated to recognize the benefit of taking in remanufacturing decision, and to identify the best pricing strategy for the remanufactured product. Ferrer and Swaminathan [10] also study the differentiated new and remanufactured product from manufacturer's perspective. The objective of the models is finding optimal prices and quantities of new and remanufactured products that maximize profit. Models are developed for monopoly and duopoly environments, for two periods, multi-period and infinite planning horizon. Similarly, Ovchinnikov [11] develops a model for finding optimal prices and quantity of remanufactured products that maximize profit, when manufacturer offers both new and remanufactured products in the market. However, he takes product differentiation approach to study customer's switching behavior, as in understanding the choices between new and remanufactured product and identifying the fraction of customer who is switching from buying new product to remanufactured one. In this model, manufacturer is the only member of supply chain considered, and he balances remanufacturing cost, demand cannibalization for new products, and additional revenue from offering remanufactured products. Another study that take product differentiation approach in the pricing model is conducted by Chen and Chang [12], where they propose dynamic pricing for new and remanufactured products under limited supply of used product, for attaining maximum profit. Even though the products are differentiated, but they are considered to be partially substitutable.

The above mentioned pricing models take only one member of supply chain as the decision maker, which is the manufacturer. However, in a closed-loop supply chain, there are other parties that also play significant roles in pricing decisions, such as retailer and collector of used product. Considering only one of the supply chain members in making pricing decision might lead to sub-optimality. Therefore, we propose a pricing model that considers not only manufacturer, but also retailer and collector in making pricing decision under product differentiation approach.

There are also other works that involve more than one party of the supply chain in the pricing decision. $\mathrm{Wu}$ [13] considers both OEM and remanufacturer in the pricing model, even though the interest of involving OEM is in investigating the product design strategy. Also, the setting of this model is placing remanufacturer as OEM's competitor since remanufactured product is assumed to cannibalize OEM's new products' sales. Therefore, OEM needs to determine the optimal level of interchangeability in his product design, since increasing the level of interchangeability would lower OEM production cost but also lower remanufacturer's cost in cannibalizing OEM's product. On the other hand, remanufacturer evaluates his pricing strategy, either taking low or high pricing strategy. Wu [14] extends his work by considering another OEM's product design strategy that could influence remanufacturer's pricing strategy, i.e. degree of disassemblability. When the degree of disassemblability is high, OEM is at risk of facing price competition with remanufacturer, because it would reduce remanufacturer's recovery cost in cannibalizing OEM's new product, even though it also reduces OEM production cost. However, both models have not considered collector's role in the pricing model, while it is obvious that acquisition price could influence the quantity of returned product and transfer price would affect the remanufacturing cost. Both prices are controlled by collector. Gan et al. [15] involve three members of the supply chain, namely manufacturer, collector, and retailer. They propose pricing decision models to optimize the wholesale and retail prices for new and remanufactured short life-cycle products, as well as the acquisition price. They also investigate the effect of diffusion rate in a time-dependent demand. Furthermore, Gan et al. [15] extend their work to consider separate sales channel, where new product is sold via retailer, and remanufactured product is offered under manufacturer's direct channel such as factory outlet or online store [16].

Despite the key characteristic of remanufacturing i.e. recovering a used product into 'as good as new', remanufactured product is often perceived to be inferior to new product; therefore it has lower value in consumer's willingness to pay (Souza[17], Agrawal [18] et al.). In addition, the perceived quality and risk could influence the purchase intention (Wang and Hazen [19], Hazen et al. [20]). To increase the perceived quality of the remanufactured product, manufacturer offers a certain warranty level, since one of the three roles possessed in warranty is being a signal to product reliability (Balachander [21], Gal-Or [22]). Another role of warranty is insurance and protection, where consumer could transfer the risk of product failure to 
seller and manufacturer (Heal [23]). In this paper, we would like to extend the previous work in Gan et al. [15] regarding pricing decision for new and remanufactured short life-cycle product, and include the warranty factor into the model.

\section{Methods}

The system is a closed-loop supply chain with two members, namely manufacturers and retailer. Manufacturer performs the process of manufacturing new products as well as remanufacturing used products. Retailer buys new and remanufactured products at wholesale prices and sells them to the end-customers at retail price. After a certain period of usage, manufacturer starts to buy used products (core) from end-customers and then remanufacture the cores. By that time, end-customers have the option to buy new or remanufactured products that are sold with different prices. Manufacturer offers warranty and allows variability in its level. The base level is the typical warranty provided for remanufactured product, where we set as zero warranty level. The higher the warranty level, the higher the protection and benefit given to the customer, for example: longer length of warranty, additional pick-up and delivery service.

The pricing decision is conducted under an independent pricing scenario with Stackelberg game. Manufacturer acts as the leader and release initial wholesale prices and warranty level. The retailer then uses that information to find her optimum prices. Finally, manufacturer updates her prices to find the optimum prices and the optimum warranty level. The product considered in this model is single item, short life cycle as in vulnerability to obsolescence of function and/or desirability. In term of product life cycle theory, such products will have short introduction, growth and maturity periods, before declining fast. Typical products with this kind of behavior are mobile phone, laptop, hi-tech gadget, and network equipments. Demand of the product will be dependent to time and price. Since remanufactured short life-cycle product is often perceived as having lower quality compared to new product, customer's willingness to pay is likely different towards new and remanufactured products (Souza [17], Lund and Hauser [4], Guide and Li [24], Subramanian [25]). Therefore, it is important to differentiate these two products and accommodate the product differentiation into the pricing model. The optimization modeling is undertaken to find optimal prices and warranty level that maximize the total profit.

\section{Notations:}

Decision Variables

$P_{n w}:$ new product's wholesale price

$P_{r w}:$ remanufactured product's wholesale price
$P_{n} \quad:$ new product's retail price

$P_{r}$ : remanufactured product's retail price

$w$ : warranty level

Parameters:

$P_{m}$ : maximum price, the upper limit of customer's willingness to pay

$t_{1}$ : time when the remanufactured product starts to be introduced to the market

$\mu$ : time when the new product's demand reaches its peak

$t_{3}$ : time when the remanufactured product's demand reaches its peak

$T$ : time when the demands end

$U$ : maximum possible demand for new product

$d_{0}$ : demand at the beginning of new product's introduction (when $t=0$ )

$\lambda$ : speed of change in new product's demand

$V$ : maximum possible demand for remanufactured product

$d_{r 0}$ : demand at the beginning of remanufactured product's introduction (when $t=t_{1}$ )

$\eta$ : speed of change in remanufactured product's demand

$c_{n}$ : unit manufacturing cost for new product

$c_{r}$ : unit remanufacturing cost for remanufactured product

$k \quad$ : demand expansion effectiveness coefficient of the warranty level

$m$ : coefficient of manufacturer's investment to provide warranty

The selling horizon consists of four periods, as in Gan et al. [16], and is depicted in Figure 1. In the first part $\left[0, t_{1}\right]$, only new product is offered to the market, while in second $\left[t_{1}, \mu\right]$ and third period $\left[\mu, t_{3}\right]$ both new and remanufactured products are offered. The market potential demand is adopted from Wang and Tung [26]. The demand patterns are constructed for both new and remanufactured product and the governing function is formulated as follows:

$d_{n}(t)=$
$\left\{\begin{array}{l}d_{n 1}(t)=\frac{U}{1+k e^{-\lambda U t}} ; 0 \leq t \leq \mu \text { where } k=\frac{U}{d_{0}-1} \\ d_{n 2}(t)=\frac{U}{\lambda U(t-\mu)+\delta} ; \mu \leq t \leq t_{3} ; \text { where } \delta=1+k e^{-\lambda U \mu}\end{array}\right.$

$d_{r}(t)=$

$\left\{d_{r 1}(t)=\frac{V}{1+h e^{-\eta V\left(t-t_{1}\right)}} ; t_{1} \leq t \leq t_{3} ;\right.$ where $h=\frac{V}{d_{r 0}-1}$

$\left\{d_{r 2}(t)=\frac{V}{\eta V\left(t-t_{3}\right)+\varepsilon} \quad ; t_{3} \leq t \leq T ;\right.$ where $\varepsilon=1+h e^{-\eta V\left(t_{3}-t_{1}\right)}$

where $d_{n}(t)$ and $d_{r}(t)$ are demand pattern for new and remanufactured products, respectively, as seen in Figure 1. The demand volume in each of the period can be found by integrating the demand function with respect to time, so the total demand for new and remanufactured products along the selling horizon are;

$$
\begin{aligned}
D_{n} & =\int_{0}^{\mu} \frac{U}{1+k e^{-\lambda U t}} d t+\int_{\mu}^{t_{3}} \frac{U}{\lambda U(t-\mu)+\delta} d t \\
& =\frac{1}{\lambda} \ln \left(\frac{\delta}{(1+k) e^{-\lambda U_{\mu}}}\right)+\frac{1}{\lambda} \ln \left(\frac{\lambda U\left(t_{3}-\mu\right)+\delta}{\delta}\right)
\end{aligned}
$$




$$
\begin{aligned}
D_{r} & =\int_{t_{1}}^{t_{3}} \frac{V}{1+h e^{-\eta V\left(t-t_{1}\right)}} d t+\int_{t_{3}}^{T} \frac{V}{\eta V\left(t-t_{3}\right)+\varepsilon} d t \\
& =\frac{1}{\eta} \ln \left(\frac{\varepsilon}{(1+h) e^{-\eta V\left(t_{3}-t_{1}\right)}}\right)+\frac{1}{\eta} \ln \left(\frac{\eta V\left(T-t_{3}\right)+\varepsilon}{\varepsilon}\right)
\end{aligned}
$$

In order to increase the remanufactured product's demand, extra warranty is provided. Therefore, it only applies to $d_{r}(t)$, which is consistent with the works in Liao et al. [27] and Gao et al. [28]. Let $k$ be the demand expansion effectiveness coefficient of the warranty level, and $w$ is the determined warranty level, then the increase in demand would be $d_{r}(t)$. $k w$. However, increasing warranty level also implies an additional cost incurred to the manufacturer as the warranty provider. Assume the cost for providing warranty follows a quadratic form $\frac{1}{2} m w^{2}$ (as in Liao et al. [27], Gao et al. [28], and Zhu et al. [29]), which is independent of the quantity. Incorporating price and warranty level into the demand functions, they become:

Demand of new product during $\left[0, t_{3}\right]$ :

$D_{n}\left(1-\frac{P_{n}}{P_{m}}\right)$

Demand of remanufactured product during $\left[t_{1}, T\right]$ :

$D_{r}\left(1-\frac{P_{r}}{P_{n}}+k w\right)$

The demand information is then shared to all members of the supply chain. Manufacturer decides the wholesale prices for new product $\left(P_{n w}\right)$ and remanufactured product $\left(P_{r w}\right)$, retailer determines the retail prices $\left(P_{n}, P_{r}\right)$, respectively. Since the product has short life-cycle, remanufacturing process is only applied to cores originated from new products.

Since this study is focusing on pricing decision, we do not make an attempt to show detailed derivation of production and operational costs, and instead treat those costs as given parameters, which consist of unit manufacturing cost for new product $\left(c_{n}\right)$, and unit manufacturing cost $\left(c_{r}\right)$. Unit manufacturing cost includes raw material, manufacturing cost, etc. Unit remanufacturing cost includes cores' acquisition, collecting cost, remanufacturing cost, etc.

\section{Optimization Models}

\section{Retailer's Optimization}

The optimization model seeks for retail prices that maximize retailer's profit, given manufacturer's initial wholesale prices $\boldsymbol{P}_{\boldsymbol{n} \boldsymbol{w}}, \boldsymbol{P}_{\boldsymbol{r} \boldsymbol{w}}$ and initial warranty level $\boldsymbol{w}$.

$$
\begin{aligned}
\max _{P_{n}, P_{r}} \Pi_{R}= & D_{n}\left(1-\frac{P_{n}}{P_{m}}\right) \cdot\left(P_{n}-P_{n w}\right)+ \\
& D_{r}\left(1-\frac{P_{r}}{P_{n}}+k w\right) \cdot\left(P_{r}-P_{r w}\right)
\end{aligned}
$$

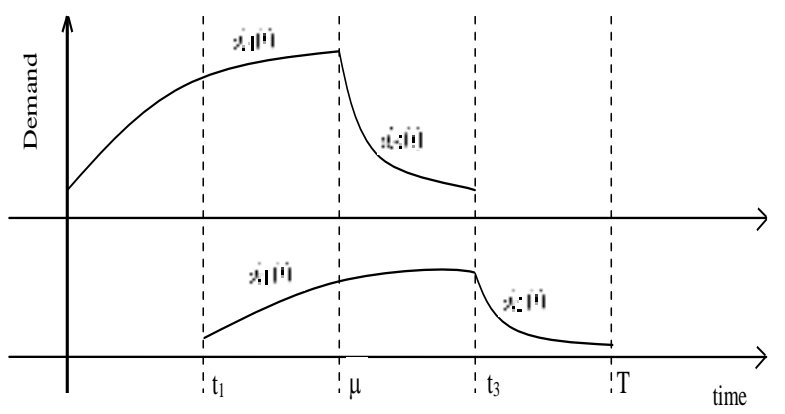

Figure 1. Demand pattern of a product with gradual obsolescence over time

First order conditions are

$\frac{\partial \Pi_{R}}{\partial P_{n}}=\frac{D_{n}}{P_{m}}\left(2 P_{n}+P_{m}+P_{n w}\right) P_{n}{ }^{2}+D_{r}\left(P_{r}{ }^{2}-P_{r} P_{r w}\right)=0$

$\frac{\partial \Pi_{R}}{\partial P_{r}}=\frac{D_{r}}{P_{n}}\left(-2 P_{r}+(1+k w) P_{n}+P_{r w}\right)=0$

$\Pi_{R}$ is concave with respect to retail prices, hence solving (8) and (9) would obtain the optimum, i.e.

$\frac{2 D_{n}}{P_{m}} P_{n}^{* 3}-\left(\frac{D_{n}}{P_{m}}\left(P_{m}+P_{n w}\right)+\frac{D_{r}}{4}(1+k w)^{2}\right) P_{n}^{* 2}+$

$\frac{D_{r}}{4} P_{r w}^{2}=0$

$P_{r}^{*}=\frac{1}{2}\left((1+k w) P_{n}^{*}+P_{r w}\right)$

\section{Manufacturer's Optimization}

$\max _{P_{n w}, P_{r w}, w} \Pi_{M}=D_{n}\left(1-\frac{P_{n}^{*}}{P_{m}}\right) \cdot\left(P_{n w}-c_{n}\right)+$

$D_{r}\left(1-\frac{P_{r}^{*}}{P_{n}^{*}}+k w\right) \cdot\left(P_{r w}-c_{r}\right)-\frac{1}{2} m w^{2}$

subject to (10), (11), and

$0 \leq P_{n w} \leq P_{n} \leq P_{m}, \quad 0 \leq P_{r w} \leq P_{r} \leq P_{n}, \quad P_{r w} \leq P_{n w}$ $w \geq 0$

The first order conditions are

$\frac{\partial \Pi_{M}}{\partial P_{n w}}=\frac{2 D_{n} P_{n}}{4 D_{n}\left(3 P_{n}-P_{m}-P_{n w}\right)+D_{r} P_{m}(1+k w)^{2}}\left(\frac{D_{n}}{P_{m}}\left(P_{n w}-c_{n}\right)-\right.$

$\left.\frac{D_{r}}{P_{n}}\left(\frac{P_{r}}{P_{n}}-\frac{(1+k w)}{2}\right)\right)\left(P_{r w}-c_{r}\right)+D_{n}\left(1-\frac{P_{n}}{P_{m}}\right)=0$

$\frac{\partial \Pi_{M}}{\partial P_{r w}}=\frac{D_{r} P_{m} P_{r w}}{12 D_{n} P_{n}^{2}-4 D_{n} P_{n}\left(P_{m}+P_{n w}\right)-D_{r} P_{m} P_{n}(1+k w)^{2}}$

$$
\left(\frac{D_{n}}{P_{m}}\left(P_{n w}-c_{n}\right)-\frac{D_{r}}{P_{n}}\left(\frac{P_{r}}{P_{n}}-\frac{(1+k w)}{2}\right)\right)+
$$$$
D_{r}\left((1+k w)-\frac{P_{r}}{P_{n}}-\frac{\left(P_{r w}-c_{r}\right)}{2 P_{n}}\right)=0
$$

$\frac{\partial \Pi_{M}}{\partial w}=D_{r} k\left(P_{r w}-c_{r}\right)-m w=0$

Because of its complexity, the above optimization problem is solved under a computational approach. In this study, we use Matlab R2014 for solving the optimization model. 
Table 1. Numerical example's results with sensitivity analysis for $\lambda, \eta$ and $k$

\begin{tabular}{rrrrrcccrcrc} 
Imb & nu & \multicolumn{1}{c}{ k } & w & \multicolumn{1}{c}{ Pn* } & Pr* & Pnw* & Prw* & w* & Profit R & Profit M & Total Profit \\
0.01 & 0.01 & 0.1 & 0.5 & $9,990.54$ & $8,292.80$ & $7,165.20$ & $6,568.95$ & 0.026 & $2,340,775.96$ & $1,228,013.47$ & $3,568,789.43$ \\
0.01 & 0.01 & 0.25 & 0.5 & $10,002.32$ & $8,409.07$ & $7,161.78$ & $6,648.67$ & 0.067 & $2,349,947.21$ & $1,239,277.18$ & $3,589,224.39$ \\
0.01 & 0.01 & 0.5 & 0.5 & $10,050.22$ & $8,881.16$ & $7,146.56$ & $6,976.71$ & 0.146 & $2,386,514.66$ & $1,285,560.31$ & $3,672,074.97$ \\
0.05 & 0.05 & 0.1 & 0.5 & $10,012.54$ & $8,306.84$ & $7,159.67$ & $6,572.79$ & 0.028 & $2,407,392.49$ & $1,265,450.92$ & $3,672,843.41$ \\
0.05 & 0.05 & 0.25 & 0.5 & $10,026.13$ & $8,433.87$ & $7,155.70$ & $6,659.61$ & 0.073 & $2,418,190.65$ & $1,278,680.19$ & $3,696,870.84$ \\
0.05 & 0.05 & 0.5 & 0.5 & $10,083.48$ & $8,951.12$ & $7,138.59$ & $7,011.64$ & 0.16 & $2,461,745.05$ & $1,335,164.53$ & $3,796,909.58$ \\
0.1 & 0.1 & 0.1 & 0.5 & $10,013.09$ & $8,307.10$ & $7,159.54$ & $6,572.82$ & 0.028 & $2,398,176.13$ & $1,260,662.08$ & $3,658,838.21$ \\
0.1 & 0.1 & 0.25 & 0.5 & $10,026.66$ & $8,433.80$ & $7,155.56$ & $6,659.41$ & 0.072 & $2,408,918.60$ & $1,273,821.74$ & $3,682,740.34$ \\
0.1 & 0.1 & 0.5 & 0.5 & $10,083.92$ & $8,949.59$ & $7,138.48$ & $7,010.42$ & 0.16 & $2,452,235.20$ & $1,329,981.63$ & $3,782,216.83$ \\
0.2 & 0.2 & 0.1 & 0.5 & $10,012.71$ & $8,306.78$ & $7,159.63$ & $6,572.70$ & 0.028 & $2,388,667.30$ & $1,255,618.33$ & $3,644,285.63$ \\
0.2 & 0.2 & 0.25 & 0.5 & $10,026.21$ & $8,432.84$ & $7,155.68$ & $6,658.86$ & 0.072 & $2,399,305.07$ & $1,268,649.61$ & $3,667,954.68$ \\
0.2 & 0.2 & 0.5 & 0.5 & $10,085.67$ & $8,945.59$ & $7,143.68$ & $7,006.34$ & 0.158 & $2,442,168.48$ & $1,322,636.49$ & $3,764,804.97$
\end{tabular}

\section{Results and Discussions}

\section{Numerical Example}

Let the new product's demand capacity parameters be $U=1,000, D_{0}=90$, and the remanufactured product's demand capacity parameters are $V=$ $500, D_{r 0}=50$. The speed of change in demands are $\lambda=0.05, \eta=0.05$. Selling horizon is divided into four time periods where $t_{1}=1, \mu=2, t_{3}=3$, and $T=4$. The unit manufacturing cost for new product $c_{n}=2,500$, unit remanufacturing cost $c_{r}=1,800$, maximum price is $P_{m}=12,000$. The initial wholesale prices are 6,000 and 4,000, initial warranty level is 0.5 . The demand expansion effectiveness coefficient $k=0.5$, the investment coefficient $m=5,000,000$. The decision variables are $P_{n}, P_{r}, P_{n w}, P_{r w}, w$ which represent the retail price of new product, retail price of remanufactured product, wholesale price of new product, wholesale price of remanufactured product, and warranty level, respectively.

a. Sensitivity analysis for speed of change in demands $(\lambda, \eta)$ and demand expansion effectiveness $(k)$

In order to study the effect of speed of change in demands and demand expansion effectiveness, the related parameters are varied as follows: $\lambda=$ $[0.01,0.05,0.1,0.2], \eta=[0.01,0.05,0.1,0.2]$, and $k=[0.1,0.25,0.5]$. Table 1 presents the results of the model optimization under the initial parameters, and the sensitivity analysis for new and remanufactured products' demand's speed of change, and the demand expansion effectiveness coefficient.

The effect of the demand expansion effectiveness coefficient can be recognized from Table 1, where the higher the coefficient, the higher total profit of the supply chain. This is understandable because higher $k$ means bigger expansion of remanufactured product's demand. Our experiment shows that there is an upper limit to this coefficient, that is, the expansion stops when remanufactured products' demand reaches the demand of new product. Since the time horizon in this study is limited to one generation of product, where remanufactured product comes from new product's end-of-use, the quantity of cores will not exceed the quantity of new product sold in the market. The speed of change in demands also has an effect in the expansion effectiveness coefficient. As seen in Figure 2, the highest total profit is reached at $\lambda=0.05$ and $\eta=$ 0.05 . This result shows that increasing the speed of change in demands does not always improving the supply chain's profit. In fact, there is an interval of demand's speed of change, where the system would reach its best, as shown in Figure 3. Therefore, managers should adjust the marketing strategy and efforts to match this best interval.

The initial warranty level set by manufacturer in the beginning of retailer's optimization does not affect the optimum warranty level. Regardless the initial value, the optimum warranty level would reach the same value. This is consistent with the previous studies, where warranty level does not influence the retailer's optimization, even though there is an increase in the remanufactured product's demand.

There is an interesting finding in the pricing of remanufactured product. Since the demand of remanufactured product is promoted by the warranty level, retailer and manufacturer can increase the wholesale and retail prices of remanufactured product to attain higher profit, when there is an increase in the expansion effectiveness coefficient, as well as an increase in the resulting optimum warranty level. Therefore, it is the manager's duty to elevate the expansion effectiveness coefficient, which could be done in many ways, such as improving product's warranty knowledge, increasing customers' awareness to product quality, and promoting the benefit of higher warranty level by transferring the product's failure risk to the manufacturer.

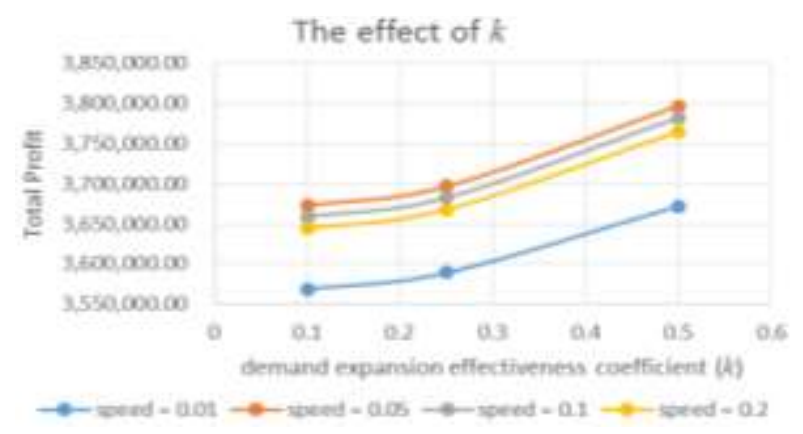

Figure 2. The effect of $k$ to the total profit 


\section{The effect of demand's speed of change}

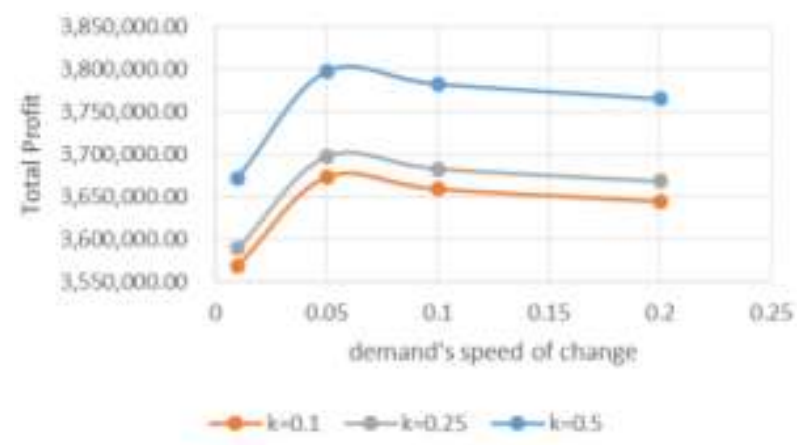

Figure 3. The effect of demand's speed of change to the total profit

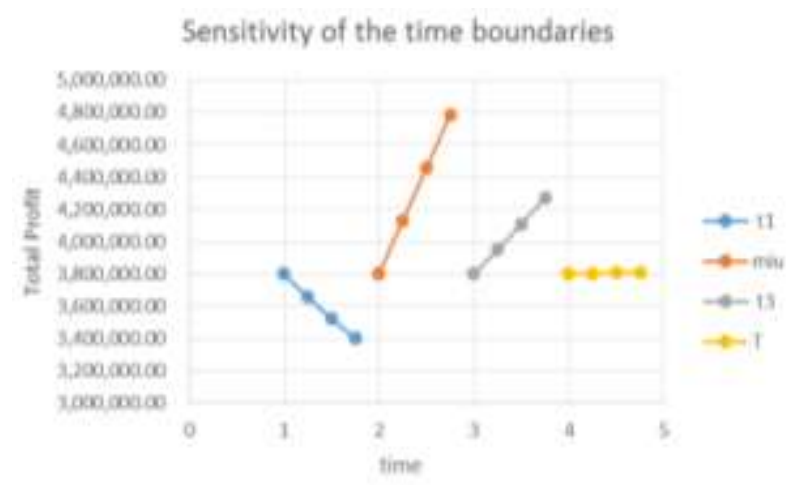

Figure 4. The effect of time boundaries

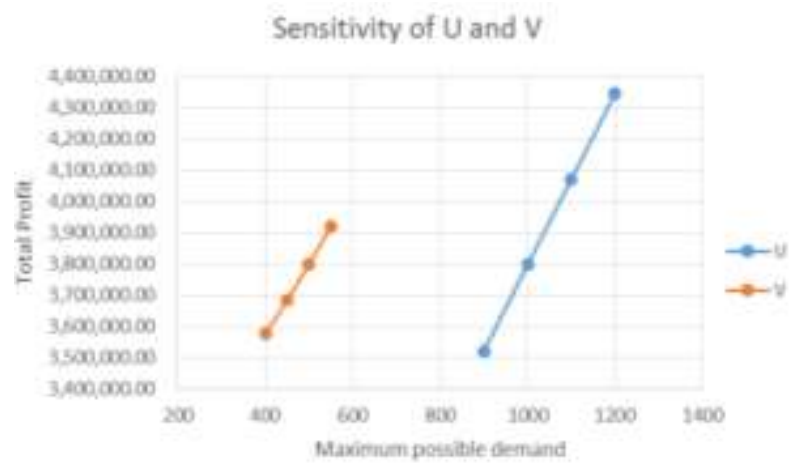

Figure 5. The effect of maximum demand

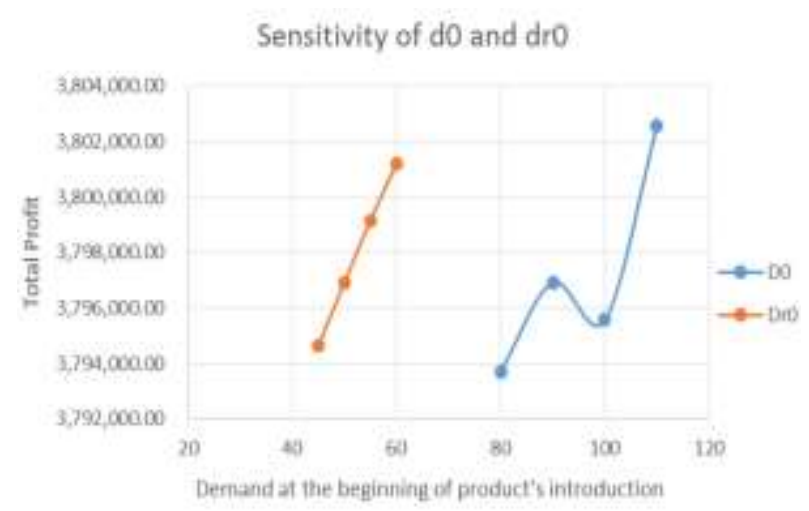

Figure 6. The effect of starting demand (demand at the beginning of product's introduction)

\section{b. Sensitivity analysis for time boundaries}

Let the time boundaries for selling horizon's period are varied individually, i.e.

$t_{1}=[1,1.25,1.5,1.75], \mu=[2,2.25,2.5,2.75]$,

$t_{3}=[3,3.25,3.5,3.75]$, and $T=[4,4.25,4.5,4.75]$.

Table 2 shows the optimization results.

The results show that delaying the introduction of remanufactured product $\left(t_{1}\right)$ is hurting both manufacturer and retailer (see Figure 4). Even though the total sales of new product is slightly increasing but the new product's price is getting lower. Also, the total sales of remanufactured product is decreasing with decreasing price as well. This condition can be explained by the significant decrease in warranty level. On the other hand, when the time of peakdemand for new product $(\mu)$ and remanufactured product $\left(t_{3}\right)$ are longer, the total profits are increasing, to the profits. Despite the longer peak time for both manufacturer and retailer. The sales of new product is increasing considerably, which contributes little slower because of the lower warranty level. As for the time for end-of-demand $(T)$, it barely effects the pricing, warranty level, and profits. Since the sales volume between $t_{3}$ and $T$ is very low compared to the whole selling horizon, the effect of extending $T$ is not significant.

Figure 4 shows that increasing peak time for demands could improve the total profits significantly, supported by the optimum warranty level. However, when the remanufactured product's introduction is delayed, the profits are reduced. Therefore, it is important that managers promote the product such that the peak time would be reacher farther ahead, and lauch the remanufactured product as early as possible.

c. Sensitivity analysis for demand capacity parameters

Demand capacity parameters are varied individually, $U=[900,1000,1100,1200], D_{0}=[80,90,100,110]$, $V=[400,450,500,550], D_{r 0}=[45,50,55,60]$.

Table 3 shows the optimization results.

The sensitivity analysis shows that both maximum demand and starting demand influence the total profit. When maximum demand is higher, both new and remanufactured products' profit are increasing. However, the pricing behavior, warranty level, and sales volume of these two products are opposite one to the other as shown in Figure 5. Increasing new product's maximum demand $(U)$ would decrease the prices, both new and remanufactured products, decrease warranty level, increase the sales of new product but decrease the sales of remanufactured product. On the other hand, increasing the maximum demand of remanufactured product $(V)$ would increase the prices, increase the warranty level significantly, decreasing the sales of remanufactured product, and increase the sales of new product. The starting demand for remanufactured product 
Table 2. Sensitivity analysis for time boundaries

\begin{tabular}{|c|c|c|c|c|c|c|c|c|c|c|}
\hline t1 & Pn* & Pr* & Pnw* & Prw* & w* & Sales-N & Sales_R & Profit R & Profit M & Total Profit \\
\hline 1 & $10,083.48$ & $8,951.12$ & $7,138.59$ & $7,011.64$ & 0.160 & 324.290 & 196.020 & $2,461,745.05$ & $1,335,164.53$ & $3,796,909.58$ \\
\hline 1.25 & $10,014.54$ & $8,810.21$ & $7,157.02$ & $6,931.55$ & 0.135 & 335.950 & 167.730 & $2,379,907.97$ & $1,275,096.67$ & $3,655,004.64$ \\
\hline 1.5 & $9,950.10$ & $8,681.13$ & $7,173.73$ & $6,858.41$ & 0.111 & 346.860 & 140.890 & $2,302,824.28$ & $1,219,805.27$ & $3,522,629.55$ \\
\hline 1.75 & $9,888.88$ &, 569.11 & $7,188.25$ & $6,801.81$ & 0.091 & 357.210 & 115.110 & $2,230,003.17$ & $1,168,144.09$ & $3,398,147.26$ \\
\hline miu & Pn* & Pr* & Pnw* & Prw* & $\mathbf{w}^{*}$ & Sales-N & Sales_R & Profit R & Profit M & Total Profit \\
\hline 2 & $10,083.48$ & $8,951.12$ & $7,138.59$ & $7,011.64$ & 0.160 & 324.290 & 196.020 & $2,461,745.05$ & $1,335,164.53$ & $3,796,909.58$ \\
\hline 2.25 & $10,030.76$ & $8,904.99$ & $7,152.46$ & $6,994.37$ & 0.156 & 373.310 & 194.120 & $2,683,907.42$ & $1,445,386.32$ & $4,129,293.74$ \\
\hline 2.5 & $9,990.83$ & $8,889.96$ & $7,168.12$ & $7,009.95$ & 0.156 & 421.420 & 191.770 & $2,905,552.68$ & $1,550,087.16$ & $4,455,639.84$ \\
\hline 2.75 & $9,956.09$ & $8,840.17$ & $7,171.69$ & $6,970.43$ & 0.151 & 469.060 & 191.390 & $3,123,529.12$ & $1,663,894.26$ & $4,787,423.38$ \\
\hline t3 & Pn* & Pr* & Pnw* & Prw* & w* & Sales-N & Sales_R & Profit R & Profit M & Total Profit \\
\hline 3 & $10,083.48$ & $8,951.12$ & $7,138.59$ & $7,011.64$ & 0.160 & 324.290 & 196.020 & $2,461,745.05$ & $1,335,164.53$ & $3,796,909.58$ \\
\hline 3.25 & $10,152.98$ & $9,097.52$ & $7,119.43$ & $7,095.27$ & 0.187 & 313.200 & 224.540 & $2,548,877.28$ & $1,399,707.86$ & $3,948,585.14$ \\
\hline 3.5 & $10,226.46$ & $9,255.43$ & $7,098.57$ & $7,185.68$ & 0.215 & 301.270 & 254 & $9,056.42$ & $1,46 \varepsilon$ & $4,107,545.83$ \\
\hline 3.75 & $10,302.57$ & $9,422.32$ & $7,076.32$ & $7,281.44$ & 0.245 & 288.780 & 284.390 & $2,730,669.37$ & $1,540,506.75$ & $4,271,176.12$ \\
\hline $\mathbf{T}$ & Pn* & Pr* & Pnw* & Prw* & $\mathbf{w}^{*}$ & Sales-N & Sales_R & Profit R & Profit M & Total Profit \\
\hline 4 & $10,083.48$ & $8,951.12$ & $7,138.59$ & $7,011.64$ & 0.160 & 324.290 & 196.020 & $2,461,745.05$ & $1,335,164.53$ & $3,796,909.58$ \\
\hline 4.25 & $10,085.94$ & $8,956.20$ & $7,137.92$ & $7,014.53$ & 0.161 & 323.870 & 197.020 & $2,464,657.20$ & $1,337,329.74$ & $3,801,986.94$ \\
\hline 4.5 & $10,087.97$ & $8,960.40$ & $7,137.37$ & & 0.162 & 323.530 & 197.850 & & 3.92 & $3,806,170.54$ \\
\hline 4.75 & $10,089.70$ & $8,963.98$ & $7,136.90$ & $7,018.96$ & 0.162 & 323.240 & 198.550 & $2,469,097.66$ & $1,340,633.40$ & $3,809,731.06$ \\
\hline
\end{tabular}

Note: Sales-N: total sales of the new product

Sales-R: total sales of the remanufactured product

Table 3. Sensitivity analysis for demand capacity parameters $\left(U, D_{0}, V, D r_{0}\right)$

\begin{tabular}{|c|c|c|c|c|c|c|c|c|c|c|}
\hline$u$ & $\mathrm{Pn} *$ & Pr* & Pnw* & Prw* & $w^{*}$ & Sales-N & Sales-R & Profit R & Profit M & Total Profit \\
\hline 900 & $0,143.39$ &, 024.26 & $7,137.32$ & $7,062.61$ & 0.166 & 283.21 & 197.09 & $2,281,556.34$ & $1,237,976.18$ & $3,519,532.52$ \\
\hline 1000 & $10,083.48$ & $8,951.12$ & 138.59 & 011.64 & 0.160 & 324.29 & 196.02 & $2,461,745.05$ & $1,335,164.53$ & $3,796,909.58$ \\
\hline 1100 & $10,039.42$ & $8,912.50$ & $7,150.20$ & $6,997.18$ & 0.157 & 364.41 & 194.43 & $2,643,399.92$ & $1,425,276.14$ & $4,068,676.06$ \\
\hline 1200 & $10,001.70$ & $8,881.56$ & $7,157.66$ & $6,988.48$ & 0.155 & 404.73 & 192.89 & $2,826,169.34$ & $1,516,214.85$ & $4,342,384.19$ \\
\hline DO & $\mathrm{Pn} *$ & Pr* & Pnw* & Prw* & $w^{*}$ & Sales-N & Sales-R & Profit R & Profit M & Total Profit \\
\hline 80 & $10,084.05$ & $8,951.62$ & $7,138.44$ & $7,011.82$ & 0.160 & 323.810 & 196.040 & $2,459,613.11$ & $1,334,108.53$ & $3,793,721.64$ \\
\hline 90 & $10,083.48$ & $8,951.12$ & $7,138.59$ & $7,011.64$ & 0.160 & 324.290 & 196.020 & $2,461,745.05$ & $1,335,164.53$ & $3,796,909.58$ \\
\hline 100 & $10,085.32$ & $8,962.85$ & $7,144.83$ & $7,028.00$ & 0.161 & 324.310 & 195.510 & $2,463,640.70$ & $1,331,928.29$ & $3,795,568.99$ \\
\hline 110 & $10,082.87$ & $8,948.64$ & $7,139.27$ & $7,008.61$ & 0.160 & 325.030 & 196.090 & $2,465,377.40$ & $1,337,178.30$ & $3,802,555.70$ \\
\hline v & $\mathrm{Pn} *$ & Pr* & Pnw* & Prw* & $w^{*}$ & Sales-N & Sales-R & Profit R & Profit M & Total Profit \\
\hline 400 & $9,975.47$ &, 731.65 & $7,167.21$ & $6,887.01$ & 0.120 & 342.560 & 151.500 & $2,333,237.66$ & $1,241,475.36$ & $3,574,713.02$ \\
\hline 450 & $10,028.00$ & $8,837.48$ & $7,153.47$ & $6,947.03$ & 0.140 & 333.680 & 173.280 & $2,395,932.84$ & $1,286,746.00$ & $3,682,678.84$ \\
\hline 500 & $10,083.48$ & $8,951.12$ & $7,138.59$ & $7,011.64$ & 0.160 & 324.290 & 196.020 & $2,461,745.05$ & $1,335,164.53$ & $3,796,909.58$ \\
\hline 550 & $10,142.28$ & $9,073.56$ & $7,122.42$ & $7,081.40$ & 0.182 & 314.340 & 219.800 & $2,530,973.49$ & $1,387,141.76$ & $3,918,115.25$ \\
\hline Dro & $\mathrm{Pn} *$ & Pr* & Pnw* & Prw* & $w^{*}$ & Sales-N & Sales-R & Profit R & Profit M & Profit \\
\hline 45 & $10,082.62$ & 947.08 & $7,139 \cdot 32$ & $7,007.64$ & 0.159 & 324.430 & 195.620 & $2,460,322.71$ & $, 334,307.23$ & $3,794,629.94$ \\
\hline 50 & $10,083.48$ & $3,951.12$ & 3.59 & $7,011.64$ & 0.160 & 324.290 & 196.020 & $2,461,7$ & .53 & $3,796,909.58$ \\
\hline 55 & $10,084.57$ & $3,953.36$ & $7,138.29$ & $7,012.91$ & 0.160 & 324.100 & 196.460 & $2,463,032.71$ & $1,336,122.07$ & $3,799,154.78$ \\
\hline 60 & $10,085.56$ & $8,955.42$ & $7,138.02$ & $7,014.08$ & 0.161 & 323.940 & 196.870 & $2,464,209.33$ & $1,336,996.70$ & $3,801,206.03$ \\
\hline
\end{tabular}

Note: Sales-N: total sales of the new product

Sales-R: total sales of the remanufactured product

changes proportionally with the total profits. However, new product's does not as shown in Figure 6. This behavior is also applied to the prices. Interestingly, the warranty level is not affected by the increased in starting demand of new product.

\section{Conclusion}

This paper studies the pricing decision and warranty level decision for new and remanufactured products in a closed-loop supply chain. We assume that providing higher level of warranty could improve the remanufactured product's demand, based on an expansion effectiveness coefficient. The optimization modeling is performed under Stackelberg game with manufacturer as the leader. We found that higher expansion effectiveness coefficient would increase the supply chain profit. Also, there is an interval of demand's speed of change, where the total profit would be at its highest. The optimum warranty level can be achieved regardless the initial warranty level set at the beginning of retailer's optimization. Furthermore, the remanufactured product's whole- sale and retail prices are influenced by the expansion effectiveness coefficient. Therefore, it is important for managers to elevate that coefficient, and perform an effective marketing strategy to keep the demand's speed of change remains in the targeted interval. The time to introduce remanufactured product is essential, as delaying it would decrease the total profit. Also, the time of peak demand for both new and remanufactured products affects the total profit, while the time to end demands does not affect it. It is also observed that maximum demand and starting demand affect the prices and profits.

However, there is a limitation to this study, i.e. we have not considered a competition between new and remanufactured products. When the warranty is at its best level, it might be possible that the remanufactured product is more attractive, hence the customer may switch from purchasing new product to remanufactured product. The issue of competition between new and remanufactured products where warranty is offered could be an interesting future study. 


\section{References}

1. Packard, V., The Waste Makers, B. McKibben, ed., Ig Publishing, 2011.

2. Hsueh, C., An Inventory Control Model with Consideration of Remanufacturing and Product Life Cycle, International Journal of Production Economics, 133(2), 2011, pp. 645-652.

3. Lebreton, B. and Tuma, A., A Quantitative Approach to Assessing the Profitability of Car and Truck Tire Remanufacturing, International Journal of Production Economics, 104(2), 2006, pp. 639-652.

4. Lund, R.T. and Hauser, W.M., Remanufacturing - An American Perspective, in 5th International Conference on Responsive ManufacturingGreen Manufacturing (ICRM 2010), 2010, pp. $1-6$.

5. Gray, C. and Charter, M., Remanufacturing and Product Design, International Journal of Product Development, 6(3-4), 2008, pp.375-392.

6. Gan, S.S., Pujawan, I.N., and Suparno, Remanufacturing of Short Life-Cycle Products, Operations and Supply Chain Management, 7(1), 2014, pp. 13-22.

7. Atasu, A., Guide, V.D.R.J., and van Wassenhove, L.N., So What If Eemanufacturing Cannibalizes My New Product Sales? California Management Review, 52(2), 2010, pp. 56-76.

8. Souza, G.C., Closed-Loop Supply Chains: A Critical Review, and Future Research, Decision Sciences, 44(1), 2013, pp. 7-38. doi:10.1111/j. 1540-5915.2012.00394.x

9. Atasu, A., Sarvary, M., van Wassenhove, L.N., Remanufacturing as a Marketing Strategy, Management Science, 54(10), 2008, pp. 17311746.

10. Ferrer, G., Swaminathan, J.M., Managing New and Differentiated Remanufactured Products, European Journal of Operational Research, 203(2), 2010, pp. 370-379.

11. Ovchinnikov, A., Revenue and Cost Management for Remanufactured Products, Production and Operations Management, 20(6), 2011, pp. 824-840.

12. Chen, J.M. and Chang, C.I., Dynamic Pricing for New and Remanufactured Products in a Closed-loop Supply Chain, International Journal of Production Economics, 146(1), 2013, pp. 153-160.

13. Wu, C.H., Product-design and Pricing Strategies with Remanufacturing, European Journal of Operational Research, 222(2), 2012, pp. 204-215.

14. Wu, C.H., Price and Service Competition between New and Remanufactured Products in a Two-echelon Supply Chain, International Journal of Production Economics, 140(1), 2012, pp.496-507.

15. Gan, S.S., Pujawan, I.N., Suparno, and Widodo, B., Pricing Decision Model for New and
Remanufactured Short-life Cycle Products with Time-dependent Demand, Operations Research Perspectives, 2, 2015, pp.1-12.

16. Gan, S.S., Pujawan, I.N., Suparno, and Widodo, B., Pricing Decision for New and Remanufactured Products in a Closed-loop Supply Chain with Separate Sales-channel, International Journal of Production Economics, 2016, (article in press) doi: 10.1016/j.ijpe.2016.08.016.

17. Souza, G.C., Remanufacturing in Closed-Loop Supply Chains, Production and Inventory Management Journal, 45(1), 2009, pp.56-66.

18. Agrawal, V.V., Atasu, A., and van Ittersum, K., Remanufacturing, Third-Party Competition, and Consumers' Perceived Value of New Products. Social Science Research Network, 2012.

19. Wang, Y. and Hazen, B.T., Consumer Product Knowledge and Intention to Purchase Remanufactured Products, International Journal of Production Economics, 181, 2016, pp.460-469.

20. Hazen, B.T., Boone, C.A., Wang, Y., and Khor, K.S., Perceived Quality of Remanufactured Products: Construct and Measure Development, Journal of Cleaner Production, 142, 2017, pp.716-726, doi:10.1016/j.jclepro.2016.05.099.

21. Balachander, S., Warranty Signaling and Reputation, Management Science, 47(9), 2001, pp. 1282-1289.

22. Gal-Or, E., Warranties as a Signal of Quality, Canadian Journal of Economics, 1989, pp. 5061.

23. Heal, G., Guarantees and Risk-sharing, The Review of Economic Studies, 1977, pp. 549-560.

24. Guide, V.D.R.J. and Li, J., The Potential for Cannibalization of New Products Sales by Remanufactured Products, Decision Sciences, 41(3), 2010, pp.547-572.

25. Subramanian, R. and Subramanyam, R., Key Factors in the Market for Remanufactured Products, Manufacturing and Service Operations Management, 2011, pp.1-31.

26. Wang, K.H. and Tung, C.T., Construction of a Model towards EOQ and Pricing Strategy for Gradually Obsolescent Products, Applied Mathematics and Computing, 217(16), 2011, pp.6926-6933.

27. Liao, B-f., Li, B-y., and Cheng, J-s., A Warranty Model for Remanufactured Products, Journal of Industrial and Production Engineering, 32(8), 2015, pp.551-558.

28. Gao, J., Han, H., Hou, L. and Wang, H., Pricing and Effort Decisions in a Closed-loop Supply Chain under Different Channel Power Structures, Journal of Cleaner Production, 112, 2016, pp.2043-2057.

29. Zhu, Q., Li, H., Zhao, S., and Lun, V., Redesign of Service Modes for Remanufactured Products and its Financial Benefits, International Journal of Production Economics, 171, 2016, pp. 231-240. 